\title{
Jovens universitários brasileiros nas linhas de produção japonesas
}

\author{
William Fugii *
}

A crescente participação de jovens universitários, ${ }^{1}$ no conjunto dos trabalhadores que tem emigrado do Brasil para o Japão marca, na última década, a história do movimento decasségui, fenômeno que tem feito muitos nipo-brasileiros ${ }^{2}$ percorrerem, a partir de meados da década de 1980 , o caminho inverso ao dos imigrantes japoneses, que chegaram ao Brasil a partir da primeira década do século $X X$.

Pesquisadores de diversas áreas do conhecimento têm se dedicado ao exame de diferentes momentos e aspectos do movimento decasségui. Este estudo privilegiou o exame da etapa recente desse movimento, quando o número de estudantes universitários brasileiros envolvidos no mesmo tem crescido significativamente.

Para a realização do trabalho recorremos, além de pesquisa bibliográfica (específica sobre o fenômeno decasségui e sobre o tema da migração num contexto mais amplo), a outros procedimentos. Realizamos entrevistas, tanto no Brasil - com jovens que já passaram pela experiência de trabalho nas linhas de montagem japonesas, ou que desejam passar por tal experiência - quanto no Japão, ${ }^{3}$ com jovens que estavam vivendo naquele momento, como trabalhadores imigrantes.

Inicialmente, para analisar o objeto específico de nossa pesquisa, procuramos obter também, junto ao Consulado Geral do Japão em São Paulo,

* Mestre pelo Programa de Pós-Graduação em Geografia Humana da FFLCH-USP. 
dados referentes ao número de vistos emitidos para estudantes universitários ao longo dos últimos vinte anos. Contudo, descobrimos que esses dados não existem, pois, de acordo com o próprio consulado japonês, nos vistos de longa permanência (categoria de visto concedido aos nipo-brasileiros, em geral) não há distinção entre estudantes e não estudantes; ou seja, o visto concedido a um estudante de 18 anos, ou a um aposentado de 60 anos, que desejam trabalhar no Japão, é o mesmo.

A ausência de tais dados em trabalhos de pesquisa relacionados ao tema decasségui, e nos relatórios estatísticos oficiais publicados anualmente pela Japan Imigration Association (Zaidan Hojin Nyukai Kyokai), do Ministério da Justiça do Japão, de onde extraímos boa parte dos dados quantitativos apresentados no trabalho, foi uma das principais preocupações durante a pesquisa.

Recorrendo a diversas outras fontes, contudo, e privilegiando a pesquisa qualitativa, encontramos elementos que reforçaram a hipótese, que orientou nossa pesquisa, de que a dinâmica atual do movimento decasségui inclui a participação crescente de jovens universitários.

Dados fornecidos pelo CIATE ${ }^{4}$ - Centro de Informação e Apoio ao Trabalhador no Exterior -, por exemplo, mostram que, entre os anos fiscais ${ }^{5}$ de 2000 e 2004 , foi crescente a porcentagem desse segmento, em relação ao total de pessoas que procuraram os serviços do órgão, conforme pode ser constatado na tabela a seguir:

\section{Consultas aos serviços do CIATE}

\begin{tabular}{|l|c|c|c|c|c|c|}
\hline Anos & $\mathbf{2 0 0 0}$ & $\mathbf{2 0 0 1}$ & $\mathbf{2 0 0 2}$ & $\mathbf{2 0 0 3}$ & $\mathbf{2 0 0 4}$ & Total \\
\hline $\begin{array}{l}\text { Pessoas que procuraram } \\
\text { os serviços do CIATE }\end{array}$ & 3.694 & 3.439 & 2.646 & 2.593 & 1.900 & 14.272 \\
\hline $\begin{array}{l}\text { Estudantes Universitários } \\
\text { (números absolutos) }\end{array}$ & 128 & 125 & 146 & 276 & 281 & 956 \\
\hline $\begin{array}{l}\text { Estudantes Universitários } \\
\text { (\%) }\end{array}$ & $\mathbf{3 , 4 6}$ & $\mathbf{3 , 6 6}$ & $\mathbf{5 , 5 1}$ & $\mathbf{1 0 , 6 4}$ & $\mathbf{1 4 , 7 8}$ & $\mathbf{6 , 7}$ \\
\hline
\end{tabular}

Fonte: CIATE - Centro de Informação e Apoio ao Trabalhador no Exterior.

Pode-se observar que, apesar do número de pessoas que procuraram o CIATE no período abordado tenha diminuído, foi crescente o número de estudantes universitários que consultou o órgão. ${ }^{6}$

João Pedro Corrêa Costa, diplomata brasileiro que serviu no Consulado Geral do Brasil em Tóquio, de 2005 a 2007, ressalta, em livro publicado em 2007, pela Fundação Alexandre de Gusmão, do Ministério das Relações Exteriores do Brasil:

“Digno de nota é o elevado número de estudantes brasileiros que migram para o Japão. Uma das explicações 
para este fato é a tentação que muitos sentem de poder trabalhar legalmente naquele país a partir dos quinze anos, por um salário de US\$1.500,00 a US\$2.000,00 mensais e assim rapidamente adquirir bens de consumo duráveis como carros, aparelhos de som, computadores, etc., aspirações que, no Brasil, demandariam um prazo e investimento em estudos muito maior" (COSTA, 2007, p. 86. Grifo nosso).

O referido autor realizou, entre abril e agosto de 2006, uma pesquisa por amostragem que resultou no recebimento de questionários respondidos por 1587 brasileiros residentes no Japão. A partir desses questionários, obteve dados muito próximos aos oficiais, fornecidos pelas autoridades japonesas, e outros que elas não informam. Entre eles, os relacionados às atividades desempenhadas no Brasil por tais decasséguis, antes de emigrarem para o Japão.

Os dados a seguir, organizados por esse autor, mostram a categoria "estudante", em primeiro lugar:

\section{Atividade econômica dos trabalhadores decasséguis antes de emigrarem para o Japão}

$\begin{array}{llr}\text { Estudante } & \mathbf{1 8 7} & \mathbf{2 6 , 2 3 \%} \\ \text { Comércio } & 149 & \mathbf{2 0 , 9 0 \%} \\ \text { Operário / Serviços manuais } & 105 & \mathbf{1 4 , 7 3 \%} \\ \text { Serviços administrativos } & 80 & 11,22 \% \\ \text { Serviços técnicos } & 69 & 9,68 \% \\ \text { Do lar } & 56 & 7,85 \% \\ \text { Autônomo } & 39 & 5,47 \% \\ \text { Bancário } & 20 & 2,81 \% \\ \text { Nível superior } & 19 & 2,66 \% \\ \text { Educador } & 16 & 2,24 \%\end{array}$

Fonte: COSTA, João P. C. De decasségui a emigrante. Brasília: Fundação Alexandre de Gusmão - Ministério das Relações Exteriores, 2007, p. 86.

Costa não menciona a porcentagem de universitários, entre os $26,23 \%$ de estudantes, mas destaca, algumas páginas antes de apresentar tais dados, 0 nível educacional dos nipo-brasileiros, citando os dados do Censo 2000 do IBGE, que revelam uma boa inserção dos mesmos no ensino superior, ainda mais se comparados com a média nacional.

De toda forma, já é possível observar que a realidade atual do movimento decasségui, em relação ao perfil dos trabalhadores envolvidos, difere bastante daquela que caracterizou o seu começo. 
O início do movimento decasségui é marcado pelo retorno ao Japão, de imigrantes japoneses que tinham chegado ao Brasil na primeira metade do século XX. Como possuíam a cidadania japonesa, não encontraram obstáculos legais para entrar no Japão. Seus filhos (niseis) - os que possuíam dupla nacionalidade, brasileira e japonesa ${ }^{7}$ - também não tiveram problemas quanto à documentação.

São poucos os exemplos similares encontrados no quadro dos mais de 190 milhões de imigrantes que se estima haver hoje no mundo, entre os quais se pode mencionar a volta de alemães da Europa Oriental à Alemanha reunificada, ou dos holandeses que retornaram das Índias Ocidentais e do Suriname aos Países Baixos (cf. COSTA, 2007, p.18).

No início do movimento decasségui, os trabalhadores que partiam do Brasil rumo ao Japão eram em sua maioria homens, entre 40 e 60 anos, chefes de família que, com o objetivo de juntar dinheiro para comprar a casa própria ou abrir o próprio negócio, emigravam geralmente sozinhos (sem a companhia da família), pretendendo permanecer de dois a três anos no Japão. Lá, conforme relatam alguns entrevistados que vivenciaram tal momento, eles moravam geralmente em pensões coletivas e, muitas vezes, dividiam o quarto com outros imigrantes brasileiros. Boa parte desse contingente possuía conhecimentos do idioma japonês, o que não diminuía, contudo, a estranheza em relação ao Japão.

A partir da consolidação do movimento decasségui e do desenvolvimento das redes entre os nipo-brasileiros no Japão, na primeira metade da década de 1990, essa realidade foi sendo gradualmente transformada. Na segunda metade dessa década, já era comum a presença de casais com filhos, além de homens e mulheres mais jovens, casados ou solteiros.

Na virada do século XXI, pode-se dizer que o movimento decasségui possui uma estrutura bastante consolidada. A presença de familiares no Japão encoraja muitos que ainda receavam passar pela experiência imigratória. Novas formas de acesso aos postos de trabalho japoneses, através da indicação direta de parentes que se encontram no país, e não apenas através das agências recrutadoras, passam a se intensificar. Em relação a este momento, pode-se dizer, também, que a maior parte dos que movimentam o fluxo é formada por pessoas que retornam ao Japão. Já são poucos (em relação ao número total) os que emigram pela primeira vez. Em outras palavras, parece que o contingente de nikkeis (descendentes de japoneses que vivem fora do Japão) do Brasil passíveis de se tornar trabalhador decasségui dava sinais de esgotamento.

Diante da diminuição do número de trabalhadores decasséguis no Japão em 1998, primeira vez que o movimento registrou valor negativo na taxa de crescimento, e do aumento inferior a 1\% em 1999 (ver tabela a seguir), as empresas japonesas começaram a articular novos planos para atrair, mesmo que por um curto período de tempo, nova parcela da comunidade nipo-brasileira que ainda não havia se submetido à experiência de trabalho no Japão. 


\section{Evolução do número de trabalhadores decasséguis brasileiros no Japão (1985-2009) ${ }^{8}$}

\begin{tabular}{|c|c|c|}
\hline Ano & $\begin{array}{l}\text { №. de brasileiros } \\
\text { registrados no Japão } 9\end{array}$ & Cresc.(\%) \\
\hline 1985 & 1.995 & \\
\hline 1986 & 2.135 & 9,21 \\
\hline 1987 & 2.250 & 5,39 \\
\hline 1988 & 4.159 & 84,84 \\
\hline 1989 & 14.528 & 249,31 \\
\hline $1990^{10}$ & 56.429 & 288,42 \\
\hline 1991 & 119.333 & 111,47 \\
\hline 1992 & 147.803 & 23,86 \\
\hline 1993 & 154.650 & 4,63 \\
\hline 1994 & 159.619 & 3,21 \\
\hline 1995 & 176.440 & 10,53 \\
\hline 1996 & 201.795 & 14,37 \\
\hline 1997 & 233.254 & 15,59 \\
\hline 1998 & 222.217 & $-4,73$ \\
\hline 1999 & 224.299 & 0,93 \\
\hline 2000 & 254.394 & 13,42 \\
\hline 2001 & 265.962 & 4,55 \\
\hline 2002 & 268.332 & 0,89 \\
\hline 2003 & 274.700 & 2,37 \\
\hline 2004 & 286.557 & 4,31 \\
\hline 2005 & 302.080 & 5,42 \\
\hline 2006 & 312.979 & 3,6 \\
\hline 2007 & 316.967 & 1,27 \\
\hline 2008 & 312.582 & $-1,38$ \\
\hline 2009 & $267.456^{11}$ & $-14,43$ \\
\hline
\end{tabular}

Fonte: Ministério da Justiça do Japão 
Nesse contexto, ouve-se falar com intensidade, a partir de 2000, do "arubaito". Na realidade, este termo já existe há muito tempo no Japão e significa um "bico", um "trabalho avulso" (HINATA, Noemia. Dicionário Japonês-Português. Japan, Kashiwashobo S.A, 1997). Mas, no âmbito do movimento decasségui, ganha um sentido próprio, específico. E ele é associado também a um "público" específico - os jovens universitários nipo-brasileiros.

De origem alemã (arbeit, que significa trabalho), a palavra arubaito indica, para esses jovens, uma espécie de "trabalho temporário" no Japão, com conotação de "programa cultural", ou "programa de férias", já que saem do país, têm a oportunidade de viajar, conhecer o Japão, quase sempre sem precisar disponibilizar nenhum recurso próprio. Utilizam apenas o dinheiro recebido pelas horas de trabalho nas firmas japonesas, o qual, na maioria das vezes, cobre, inclusive, as despesas da viagem. Os que optam por economizar, ainda conseguem em três meses, de acordo com muitos entrevistados, poupar de três a quatro mil dólares. Alguns chegam a economizar um valor ainda maior.

Inicialmente, esse "programa" era realizado somente nas férias escolares (quando o fluxo ainda é maior), do começo de dezembro ao final de fevereiro, mas com o sucesso da adesão por parte dos jovens estudantes, ele passou a ser oferecido em praticamente todas as épocas do ano.

\section{Mas o que vem a ser de fato o arubaito?}

As empresas contratadoras de imigrantes brasileiros no Japão, sempre tiveram um grande déficit de mão de obra nos finais de ano, época em que as comemorações natalinas do Ocidente demandam maiores quantidades de produtos eletrônicos importados do país. Soma-se a isso, a preferência dos decasséguis em retornar ao Brasil justamente nos finais de ano, para aproveitarem as mesmas comemorações natalinas e a virada do ano com os familiares e amigos. ${ }^{12}$

Como a produção não pode parar, muitas empresas começaram a oferecer condições especiais (como bônus salarial, prêmios em dinheiro, etc.) para que esses funcionários não deixassem as linhas de produção no período mencionado, mas mesmo assim observou-se que as medidas não foram suficientes. Os contratadores de mão de obra decasségui brasileira começaram, portanto, a tentar repor o contingente de trabalhadores que retornam ao Brasil nos finais de ano, bem como contratar novos braços para outros postos que viessem a surgir, por meio da aceitação de trabalhadores brasileiros por curtos períodos de tempo. É conhecida a exigência (até então) por parte das empreiteiras japonesas da permanência de pelo menos um ano no serviço, ${ }^{13}$ mas diante da conjuntura exposta esse critério parece ter sido relativizado.

Ofereceram, ainda, algumas pequenas vantagens - subsídio de parte do aluguel, por exemplo - para que, mesmo por um curto período de tempo, fosse viável economicamente para o candidato a experiência no Japão. 
Essas pequenas "vantagens", junto com a possibilidade de trabalhar por apenas três meses, começaram a atrair aqueles estudantes universitários nipo-brasileiros que desejavam conhecer o Japão (e por que não "juntar um dinheirinho?"), mas que não podiam ou não queriam emigrar para lá por um longo período de tempo, justamente por estarem inseridos no ensino superior. Muitos deles tinham pais e familiares no Japão que, com a possibilidade dos filhos e parentes viajarem para o país, até desistiam de retornar ao Brasil, já que o objetivo principal era matar a saudade dos mesmos.

E esses jovens voltaram trazendo as novidades da Terra do Sol Nascente, contando as experiências (as boas e as ruins), que de certa maneira aguçaram a curiosidade e interesse de amigos da faculdade, da vizinhança, enfim, dos diversos grupos com quem mantêm sua sociabilidade.

Mesmo crescendo em números, esse "programa de arubaito" esbarrava, contudo, no estigma do movimento decasségui. Para muitos descendentes, ainda hoje, ser trabalhador decasségui significa expor seu fracasso no Brasil, e muitos camuflam possíveis situações de insegurança somente para não se submeterem ao movimento.

Enxergando a potencialidade desses jovens universitários para ajudar a suprir (pelo menos parcialmente) a demanda de mão de obra no Japão, os contratadores passaram a investir nos programas de arubaito, e para isso trataram logo de reverter o estigma mencionado, separando em categorias diferentes o "trabalhador decasségui" do "estudante arubaito".

Em outras palavras, quando os agricultores descontentes com a situação adversa no Brasil, quando o pequeno empresário falido e desamparado, quando o pai de família desempregado ou mal empregado, já se encontravam seduzidos pela remuneração das linhas de montagem japonesas e, mesmo assim, o contingente não era suficiente, o "mercado decasségui" imputou novas estratégias para atrair um novo segmento da comunidade nipo-brasileira.

A produtividade e a fácil adaptação desses jovens às formas de organização do trabalho nas empresas japonesas, onde a informática, a robótica e recursos tecnológicos de última geração estão presentes, fazem com que as empresas direcionem cada vez mais o olhar para os universitários nipo-brasileiros. Se no começo eles representavam apenas uma alternativa para tais empresas, tornaram-se hoje, para muitas delas, um perfil objetivado, conforme ressaltam representantes de algumas empresas recrutadoras, entrevistados tanto no Brasil quanto no Japão.

\section{As estratégias das empresas recrutadoras para atrair os jovens universitários}

A principal estratégia para atrair maciçamente os universitários nipobrasileiros foi, como adiantado, mudar o "status" da experiência imigratória. E podemos dizer com convicção que ela teve êxito. Nenhum dos jovens que entrevistamos se inseriram no que eles entendem por movimento decasségui. $E$ 
isto ocorre não devido ao "tempo" que eles permanecem no Japão, pois alguns entrevistados haviam prolongado o período do "programa" e permanecido por mais de um ano no país, com a matrícula da faculdade trancada no Brasil. Não se consideram decasséguis por ainda estigmatizarem o movimento.

Ângela, uma jovem de São Paulo, que embarcou para o Japão em 2007, aos 18 anos, no final do primeiro ano da graduação em Administração, e permaneceu por mais de um ano no país, explicitou este aspecto. Apesar de relatar que trabalhava 13 horas por dia "fazendo a mesma coisa e sem sair do lugar", que era alvo de preconceitos, que tinha dores no corpo devido ao trabalho excessivo, que se sentia alienada, etc. - características de qualquer trabalhador decasségui -, ao ser questionada se retornaria ao Japão a trabalho, a resposta foi taxativa: "Só se for arubaito de novo... nada mais que isso... eu me amo!" - deixando claro suas apreensões diferenciadas entre "ser decasségui" e "ser arubaito".

Inicialmente, para atrair a atenção do segmento específico que estamos abordando, muitas agências recrutadoras começaram a "marcar presença" em locais frequentados pelos jovens universitários nikkeis. O patrocínio de festas e de eventos esportivos da comunidade nipo-brasileira se tornou comum para as empresas contratadoras de decasséguis.

O fornecimento de uma espécie de "certificado" por ter trabalhado em uma montadora de carros, indústria de eletrônicos ou qualquer outra atividade no Japão, também pôde ser observado. Isso, para aproximar cada vez mais a experiência do arubaito à de um "estágio" remunerado fora do país.

Grandes investimentos em publicidade nos jornais e revistas voltados à comunidade nipo-brasileira também tiveram bastante peso. Nos anúncios, chamadas diferenciadas para o estudante arubaito e para o trabalhador decasségui - ainda que essa pretendida diferença não possa ser facilmente reconhecida.

Analisando duas propostas de serviço (ambas para a Sony, de Omigawa) da agência brasileira Sawatur, representante da empreiteira japonesa Twenty First, uma voltada aos trabalhadores decasséguis em geral e outra aos arubaitos, só encontramos diferenças em relação a dois itens da proposta: (1) a moradia - as vantagens para os arubaitos são, além de um desconto de dez mil ienes (aproximadamente cem dólares) no aluguel (que de trinta mil foi para vinte mil ienes), se realmente permanecerem por apenas três meses no trabalho, a isenção da taxa de cinco mil ienes, referente ao "kit de cama"; e (2) a idade - o limite máximo de idade para os arubaitos atinge 30 anos para o sexo masculino e 40 anos para o feminino, ao passo que para os trabalhadores em geral atinge, respectivamente, 40 e 45 anos.

Local de trabalho, tipo de serviço, salário, horas-extras, horário de trabalho, condução, refeição e infraestrutura em geral, são exatamente idênticos.

Entre as empresas que costumam contratar um número expressivo de arubaitos, anualmente, podemos destacar, além da Sony, fabricante de câmeras digitais, aparelhos de som e eletrônicos em geral (com fábricas em diversas 
regiões do Japão), a Suzuki, montadora de carros e motos, além de muitas outras menos conhecidas pelos brasileiros.

Outra estratégia utilizada pelas agências recrutadoras de trabalhadores decasséguis, para atrair os jovens universitários nipo-brasileiros, foi associar o arubaito a programas de intercâmbio em outros países, entre eles Estados Unidos, Canadá, Austrália e países da Europa.

Intercâmbio + arubaito = Interbaito!

Essa forma de contratação funciona da seguinte maneira: o jovem universitário nipo-brasileiro que deseja estudar em qualquer país do mundo, mas precisa de recursos financeiros para tal empreitada, submete-se por alguns meses ao trabalho em alguma empresa no Japão e, após juntar o valor necessário, segue para o país que deseja.

Na realidade, a agência recrutadora no Brasil não possui nenhum interesse no "pós-Japão". Faz parcerias com empresas de intercâmbio conhecidas pelos jovens estudantes, para aumentar seu prestígio frente a eles e, assim, garantir mais braços para os postos de trabalho no Japão, seu objetivo de fato.

É possível encontrar inúmeros anúncios do Interbaito nos sites de agências recrutadoras de trabalhadores decasséguis.

O Interbaito também aparece sob outras denominações, mas com a mesma finalidade. After arubaito, world baito, sekai arubaito (sekai = mundo), enfim, cada agência adota o nome que sua criatividade lhe sugerir - objetivando, contudo, arregimentar jovens com o perfil abordado neste artigo.

Em outras palavras, sob a aparência de estágio ou de intercâmbio, trata-se, na realidade, de uma forma de contrato de trabalho.

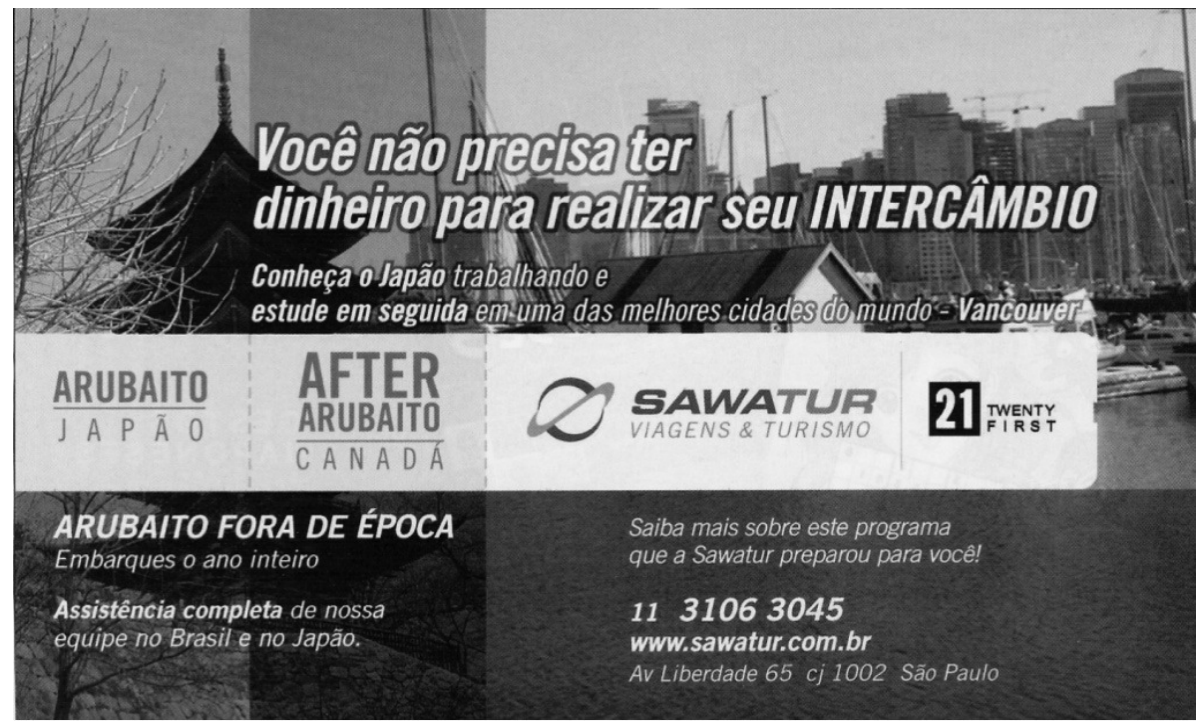

Publicidade veiculada na Revista Made in Japan, 2007. 
$\mathrm{Na}$ Internet, existem dezenas de páginas criadas pelos jovens nikkeis, relacionadas ao arubaito. No site de relacionamentos Orkut, por exemplo, podemos encontrar inúmeras comunidades, criadas para a troca de experiências, expectativas e, em grande medida, para avaliar as empresas contratadoras.

Até mesmo em publicações não direcionadas especificamente aos jovens nikkeis, já é possível observar o destaque dado a essa característica atual do movimento decasségui. A edição 244, de outubro de 2007, da Revista Super Interessante, por exemplo, traz uma reportagem especial, de seis páginas, sobre o arubaito, destacando a experiência de um jovem que passou dois meses trabalhando até 15 horas por dia, numa indústria de eletrônicos, na província de Shizuoka.

Existem, em relação ao tema deste artigo, inúmeros aspectos a serem abordados como, por exemplo, a contribuição dos jovens universitários para as mudanças nas redes de contratação dos imigrantes nipo-brasileiros, ou, em outras palavras, a contribuição deles para a diminuição da importância das agências recrutadoras no Brasil; as motivações subjetivas envolvidas na experiência imigratória desses jovens, que emigram para a terra dos ancestrais e não para qualquer lugar; o consumismo que, em parte, também os atrai ao Japão, etc., revelando novas possibilidades de pesquisa sobre a temática decasségui e seus desdobramentos, que ainda estão longe de esgotar-se.

\section{Considerações finais}

Estima-se que a crise econômica mundial, que atingiu fortemente o Japão, tenha provocado, do final de 2008 ao início de 2010, o retorno de quase 50 mil trabalhadores nikkeis ao Brasil, além de interromper "temporariamente" o fluxo iniciado na década de 1980.

Certamente, esse foi um dos piores momentos da história do movimento decasségui, que, todavia, começa a mostrar sinais de recuperação. A redução das concessões de subsídios do governo japonês para o retorno dos imigrantes e o desempenho econômico do país nos últimos meses revelam tais perspectivas.

Timidamente, as empresas têm retomado as contratações de trabalhadores do Brasil. E, nesse momento em que as vagas não são abundantes como antes, as exigências quanto à qualificação do imigrante têm sido maiores, levando-nos a acreditar que os jovens universitários terão papel fundamental e estratégico na retomada do fluxo migratório.

Mais do que isso, nossa hipótese é de que a grande inserção de jovens universitários no movimento decasségui, nos últimos tempos, antecede, na realidade, a inauguração de uma nova fase, na qual a consanguinidade (e a ideia de preservação cultural) poderá ser relativizada para, a exemplo do que acontece em muitas partes do mundo, ser valorizada majoritariamente pelo Japão - nação preocupada com o envelhecimento de sua população e com a manutenção das conquistas proporcionadas pelo desenvolvimento econômico da segunda metade do século XX - a qualificação do imigrante, seja ele de origem nipônica ou não. 


\section{Notas}

1 - Este artigo apresenta parte dos resultados de pesquisa apresentada como dissertação de mestrado, sob o título "Jovens universitários brasileiros nas linhas de produção japonesas: uma contribuição ao estudo do fenômeno migratório entre o Brasil e o Japão (1908 - 2008)", ao Programa de Pós-Graduação em Geografia Humana da FFLCH - USP, defendida em 2009.

2 - O movimento decasségui apresenta, entre as peculiaridades que o distinguem dos demais fluxos migratórios, a migração seletiva, aberta apenas aos descendentes (e cônjuges) de imigrantes japoneses que a partir da primeira década do século XX chegaram aos países da América Latina, entre eles o Brasil. Esse critério foi estabelecido pelo governo japonês com o objetivo de preservar os elementos culturais do país.

3 - Em julho de 2006, como atividade do Programa de Mestrado, o pesquisador viajou para o Japão com o objetivo de realizar trabalho de campo voltado à compreensão da inserção, no país, dos jovens universitários nipo-brasileiros desenvolvendo programas de arubaito (esse termo será abordado adiante).

4 - Órgão relacionado ao Ministério da Saúde, Trabalho e Bem-Estar Social do Japão, que tem por objetivo prestar serviços de informação e de orientação sobre os mais variados aspectos da sociedade e cultura japonesas aos nipo-brasileiros e seus cônjuges, principalmente os relacionados ao trabalho no país.

5 - O ano fiscal japonês vai de abril até março do ano subsequente. Portanto, os dados apresentados na tabela abrangem o período de abril de 2000 a março de 2005.

6 - A redução do número de pessoas que consultou o CIATE, no período abordado, é um indicativo da redução de ingressantes no movimento decasségui. Os trabalhadores que retornam ao Japão, dificilmente fazem uso dos serviços do órgão.

7 - Nas primeiras décadas do século XX, era comum entre os imigrantes japoneses a prática de registrar o nascimento dos filhos no consulado japonês. Assim, eles adquiriam também a nacionalidade japonesa. Essa prática tornou-se mais rara após a II Guerra Mundial, quando se consolida o enraizamento dos japoneses e seus descendentes no Brasil. A derrota do Japão representou para os imigrantes japoneses - que até então acreditavam na ascendência divina do imperador e na invencibilidade do exército imperial japonês - um duro golpe, o desmoronamento de um sonho (cf. SAKURAI, 1993 e OCADA, 2006). A partir do momento em que o imperador japonês declara a rendição do país, pedindo que seus súditos "tolerassem o intolerável e suportassem o insuportável" (MORAIS, 2000), o desejo de rever a terra natal, que ainda continuava vivo no imaginário dos imigrantes, é silenciado. Vale lembrar que o rompimento das relações diplomáticas do Brasil com os países do Eixo (entre eles, o Japão), em 29 de janeiro de 1942, também contribuiu para o abandono da prática mencionada. Como representantes de uma nação inimiga, os imigrantes japoneses foram duramente perseguidos durante a guerra e, consequentemente, desencorajados a realizar tal procedimento.

8 - É importante salientar que esses números não são precisos, pois não incluem os iseis (os próprios imigrantes japoneses que retornaram ao Japão no começo do movimento decasségui, nem os niseis (filhos dos imigrantes japoneses) possuidores de dupla cidadania. Estes dois grupos entram no país com o passaporte japonês, o que impossibilita a quantificação dos mesmos.

9 - Esses números correspondem ao total de brasileiros registrados no Japão, e que se encontram presentes no país no momento do levantamento dos dados. Não são considerados aqueles que retornaram ao Brasil. Se essas pessoas retornarem ao Japão, entrarão nas estatísticas correspondentes aos anos em que permaneceram no país. 
10 - Ano da Emenda Constitucional Japonesa, que alterou a Lei de Imigração do Japão e que passou a autorizar descendentes de japoneses até a segunda geração (nisei e sansei) a entrarem no país para trabalhar.

11 - A redução significativa neste ano está relacionada à crise econômica mundial que atingiu fortemente o Japão. O país sentiu de maneira profunda os efeitos da queda das exportações de seus produtos industrializados, bem como da redução do consumo interno. Para minimizar os problemas relacionados à elevação do número de desempregados no país em decorrência da crise, o governo japonês passou a conceder subsídios para o retorno dos imigrantes, o que contribuiu para que mais de 45 mil trabalhadores decasséguis brasileiros deixassem o Japão no período.

12 - Essa realidade foi constatada a partir de entrevistas com representantes de algumas empresas japonesas que contratam imigrantes nipo-brasileiros, e a partir de entrevistas com os próprios trabalhadores decasséguis.

13 - Embora não haja nenhum instrumento legal que obrigue os trabalhadores decasséguis a permanecerem numa mesma fábrica por um período de tempo mínimo estipulado, a maioria das empreiteiras contratadoras exigia, até então, o compromisso do funcionário em permanecer pelo menos um ano no emprego. Isso porque, segundo os contratadores, são grandes as despesas iniciais para o recrutamento do funcionário (luva para locação de residência, treinamento inicial, registros legais de estrangeiro, etc.).

\section{Referências}

COSTA, João Pedro Corrêa. De decasségui a emigrante. Brasília: Fundação Alexandre de Gusmão - Ministério das Relações Exteriores, 2007.

DEMARTINI, Zeila B. F. Vivências diferenciadas de três gerações de japoneses em São Paulo. In: Travessia - Revista do Migrante. São Paulo. Publicação do CEM, no 35, set - dez. 1999, p.10-16.

HINATA, Noemia. Dicionário Japonês-Português. Japan: Kashiwashobo S.A, 1997.

KAWAMURA, Lili. "Para onde vão os brasileiros? Campinas: Editora da Unicamp, 1999.

MORAIS, Fernando. Corações Sujos. São Paulo: Companhia das Letras, 2000.

OCADA, Fabio Kazuo. A tecelagem da vida com fios partidos: as motivações invisíveis da emigração dekassegui ao Japão em quatro estações. Tese de doutorado em Sociologia. UNESP, 2006.

ROSSINI, Rosa Ester. O novo enraizamento: a conquista do espaço pelos nikkeis do Brasil no Japão. Anais do XIII Encontro da Associação Brasileira de Estudos Populacionais. Ouro Preto, Minas Gerais, 2002. 18p.

SASAKI, Elisa M. Movimento dekasegui e experiência migratória e identitária dos brasileiros descendentes de japoneses no Japão. In: REIS, Rosana Rocha e SALES, Teresa. Cenas do Brasil Migrante. São Paulo: Boitempo Editorial, 1999, p.243-274.

\section{RESUMO}

A partir de meados da década de 1980, teve início o fluxo migratório de nipo-brasileiros para o Japão, que ficou conhecido como Movimento Decasségui. Ao longo de pouco mais de duas décadas de existência, a expressividade desse fluxo pôde ser conhecida, por meio dos inúmeros estudos realizados sobre o tema. Pesquisadores de diversas áreas do conhecimento analisaram o fenômeno, a partir das diversas abordagens que ele comporta: econômica, social, cultural, psicológica, jurídica, linguística, tributária, educacional, etc. 
Este artigo privilegiou o exame da etapa recente do movimento decasségui, caracterizada pela crescente participação de jovens universitários nele inseridos. São apresentadas, entre outros aspectos, as razões que levaram as empresas japonesas que utilizam mão de obra imigrante a direcionarem seu olhar para esses jovens, bem como as estratégias das agências recrutadoras para atrair esse segmento da comunidade nipo-brasileira.

Em outras palavras, procura-se compreender como os jovens universitários nipo-brasileiros, sob a fachada de programa de férias, estágio ou algo parecido, têm sido arregimentados para o trabalho nas linhas de produção no Japão.

Palavras-chave: decasségui; arubaito; migração.

\begin{abstract}
Migration flows of Japanese-Brazilians to Japan, known as Dekasegui Movement, started in the mid '80s. Throughout a little more than two decades of existence, the relevance of this flow has been widespread through innumerable research studies conducted about the subject. Researchers in various areas of knowledge analyzed this phenomenon from the different approaches it comprises, and which relate to economy, society, culture, psychology, law, linguistics, taxes, education, just to name a few.

This article focuses on the observation of the recent phase of the Dekasegui movement, which is characterized by the growing participation of young university students. Among other aspects, this study discusses the reasons that led Japanese companies that use immigrant workforce to direct their look to these youngsters, as well as the strategies used by recruiting agencies to attract this segment of the Japanese-Brazilian community.

In other words, it seeks an understanding of how young Japanese-Brazilian university students are being selected to work in Japanese production lines under the pretext of taking part in vacation programs, internships or similar activities.
\end{abstract}

Keywords: dekasegui; arubaito; migration. 
